\title{
REPORT OF THE COMMITTEE ON REGIONAL MEETINGS
}

I

\section{Advantages of Regional Meetings}

(1) Many members of the Catholic Theological Society who for various reasons (finances, distance, schedule, etc.) find it inconvenient to attend the annual national meeting, may well find it possible to attend a regional meeting.

(2) Regional meetings will provide opportunities for more members to contribute actively to the work of the CTSA by papers, discussions, and seminars.

(3) With regional meetings the CTSA will gradually become more of a year-round activity rather than the sheerly annual affair with which it has become identified in the minds and experience of many.

(4) The experience of similar organizations, such as the American Catholic Philosophical Association, indicates that regional meetings are a definite source of new memberships.

II

\section{Possible Regions}

Detailed analysis reveals that CTSA membership is mostly concentrated in six areas. These areas are listed below, with the following data for each:

(a) a key city or sector within the area;

(b) the total area embraced;

(c) number of CTSA members within the area.

(1) Boston Massachusetts Rhode Island

37 members

(2) Metropolitan New York New York State New Jersey Connecticut

93 members 
(3) Baltimore-Washington Maryland

84 members Dist. of Columbia

(4) Cleveland Ohio

Kentucky

24 members

Michigan

(5) Chicago

Illinois

Indiana

Wisconsin

54 members

(6) Quebec-Ontario

Quebec

Montreal

Ottawa

21 members

Toronto

It must be emphasized that the cities listed are not necessarily the best centers for regional meetings. They are simply key cities, in the sense that they happened to be the sections where CTSA membership is heavily concentrated.

The division of regions suggested above obviously leaves a number of problems unsolved. For example, certain large areas such as the West Coast, the Southeast, in fact the whole region west of the Mississippi River, have not been mentioned at all. These areas offer special problems, primarily because their CTSA membership is so scattered and relatively small.

Further, a special problem arises in assigning certain large cities (such as Philadelphia, Detroit, Minneapolis, St. Paul) to the six regions listed.

\section{III}

\section{Organizational Framework}

(1) It is expected that in each instance the initiative for a regional meeting will come from within the region itself.

(2) It is suggested that, before the close of this Convention, the president of the CTSA name a provisional chairman for each region listed above, and perhaps also for certain larger areas not listed. The task of each provisional chairman is to sound out the sentiment within his region with respect to regional meetings, and to communicate his findings to the Chairman of the Committee on Current Problems. It is further suggested that the names of the provisional chairmen be announced at this Convention, and that the members within each region be urged to contact the chairman in question. 
(3) In the event that regional meetings are to be held, the following experiences of similar organizations are offered as a guide to procedure:

(a) Regional meetings will be most successful if a religious house or a seminary in the area acts as host.

(b) The order of time should be such that those attending need not be away overnight.

(c) The meeting should be limited either to an afternoon session alone or to a late morning and an early afternoon session.

(d) If there are morning and afternoon sessions, the members and not the host institution shall pay for the lunch.

(e) Since it is desirable to emphasize discussion and audience participation, no more than two papers should be read.

$(f)$ The Chairman of the Committee on Current Problems should receive copies of the papers and discussions at the regional meetings, with a view to possible inclusion in the annual Proceedings of the CTSA.

(g) The general treasury of the CTSA shall assume reasonable clerical expenses.

Walter J. Burghardt, S.J., Chairman, EDMOND D. BENARD,

JoHN F. X. SWEENEY, S.J. 